\title{
Evaluation of two single-factor models of metabolic syndrome: a confirmatory factor analysis for an adult population in Beijing
}

Da Huo ${ }^{1,2}$, Wei Wang ${ }^{1,3}$, Xia Li ${ }^{1,2}$, Qi Gao ${ }^{1,2}$, Lijuan Wu ${ }^{1,2}$, Yanxia Luo ${ }^{1,2}$, Youxin Wang ${ }^{1,2}$, Puhong Zhang ${ }^{4}$ and Xiuhua Guo ${ }^{1,2^{*}}$

\begin{abstract}
Background: Prevalence of metabolic syndrome is high and increasing in China. The causation of this disorder is, yet, to be fully understood. Several studies with confirmatory factor analysis have been performed to investigate the core of the disease in some races other than Chinese, and amongst the other studies, they have yielded a sound model fit. This study was to evaluate and compare two single-factor models of the underlying factor structure of metabolic syndrome in a Chinese population using confirmatory factor analysis.

Results: Findings showed that in a Chinese sample of 7,472 individuals, Model 1 (with waist circumference, triglycerides/HDL-C ratio, fasting plasma glucose and mean artery pressure) yielded good level of fitness (SRMR $<$ $0.08, \mathrm{CFI}>0.96$ and RMSEA < 0.10) in men and women of all age groups; and Model 2 (with waist circumference, triglycerides, fasting plasma glucose and systolic blood pressure) fitted well in men aged 18-34 and over 60 and in all women, except in men of 35-59 (RMSEA = 0.142). In comparison, Model 2 were shown to be better fit (with relative larger $\mathrm{GFI}$ and smaller $\mathrm{AIC}, \mathrm{BIC}, \mathrm{CAIC}$, and $\mathrm{EVIC}$ ) in women of all age groups and in men of 18-34 and over 60 years old; Model 1 had a better fit in men between 35 and 59.

Conclusions: This study suggests that the single-factor model of metabolic syndrome with waist circumference, triglycerides, fasting plasma glucose and systolic blood pressure are plausible in women of all age groups and young and senior men in Beijing. The model with waist circumference, triglycerides/HDL-C ratio, fasting plasma glucose and mean artery pressure fits middle-aged men.
\end{abstract}

Keywords: Metabolic syndrome, Confirmatory factor analysis, Single-factor model, Chinese

\section{Background}

The metabolic syndrome (MetS) is conceptualized as a constellation of multiple, closely-related metabolic disorders. It is a major global public health problem in both developed and developing countries [1]. The commonly encompassed features of MetS are insulin resistance, hypertension, abdominal obesity, and dyslipidemia [1-4]. Those seemingly unrelated biological processes have been proved to occur at a frequency higher than by mere chance. In 1988, Reaven proposed an underlying

\footnotetext{
* Correspondence: guoxiuh@ccmu.edu.cn

${ }^{1}$ School of Public Health, Capital Medical University, No.10 Xitoutiao, You'anmen Wai, Fengtai District, Beijing 100069, China

${ }^{2}$ Beijing Municipal Key Laboratory of Clinical Epidemiology, Beijing 100069, China

Full list of author information is available at the end of the article
}

pathophysiological causation and named it as Syndrome $X$ [5]. And the syndrome appears to increase the risk of developing cardiovascular disease and type 2 diabetes mellitus [6-9]. Although, it has been known for at least eighty years [10], the definition for MetS has been developing with time - World Health Organization (WHO) in 1999 [11], International Diabetes Federation (IDF) in 2004 [2], US National Cholesterol Education Program (NCEP) Adult Treatment Panel III (ATP III) in 2001 [12] and a modified edition in 2005 [13]. In China, Chinese Diabetes Society (CDS) [14] and Joint Committee for Developing Chinese Guidelines on Prevention and Treatment of Dyslipidemia in Adults (JCDCG) [15] also released their diagnosing criteria specifically for the Chinese population in 2004 and 2007, respectively. In
C Biomed Central

(c) 2013 Huo et al.; licensee BioMed Central Ltd. This is an Open Access article distributed under the terms of the Creative Commons Attribution License (http://creativecommons.org/licenses/by/2.0), which permits unrestricted use, distribution, and reproduction in any medium, provided the original work is properly cited. 
2009, a joint interim statement by six major institutions was released [16]. In the statement, raised waist circumference (WC), elevated triglycerides (TG), reduced highdensity lipoprotein cholesterol (HDL-C), elevated systolic and/or diastolic blood pressure (SBP, DBP), and elevated fasting plasma glucose (FPG) were included in the diagnosis criteria. WC, the indicator for central obesity, is defined as population- or country-specific.

Though the definition has been agreed upon, the mechanism of MetS is still controversial [17], such as some declaring that insulin resistance might be the major cause $[5,18]$. There is debate about the essence of the MetS pertaining to which components are included and what pathologic process is central to its occurrence. The commonly included components are hypertension, obesity, elevated blood glucose, and dyslipidemia. These factors tend to cluster as a risk factor for the morbidity of cardiovascular disease, type 2 diabetes mellitus, and overall mortality $[1,13]$.

In recent years, factor analysis has been applied to shed some light on finding the "common soil" for the syndrome [19]. Exploratory factor analysis (EFA), a multi-factorial statistical procedure, is used to extract a relatively small set of latent variables from the extensively observed ones. Observed variables are directly measurable, while the latent are the underlying factors. Studies with EFA indicate differences in the number of factors extracted and the variable loadings on each factor. The inconsistence may be due to the nature of EFA and the methods applied in the extraction of variables. The variables shared in common are assumed to be the underlying latent variables [20].

Confirmatory factor analysis (CFA) is another way to evaluate the factor structures of MetS based on the theoretical foundations set by EFA [21]. It is used to analyze one or more latent causative factors underlying a concept, i.e. MetS in our study, by comparing the distribution and the established factor structure based on the known concept [22].

With a priori selected factor models from previous research, CFA can be used to compare competing models of MetS using the same dataset to determine which of the two or more hypothesized models fits best [23].

The aim of this study is to evaluate and compare two competing models of metabolic syndrome using CFA in a Chinese population. There are two single-factor models for candidate: Model 1 is by Pladevall et al. and Martinez-Vizcaino [24,25], with WC, TG/HDL-C ratio, and mean arterial pressure (MAP) as factors, but HOMA-IR (homeostasis model of assessment for insulin resistance) or fasting insulin in the original models is substituted by fasting plasma glucose referred to the latest diagnosis criteria for MetS [16]; Model 2 is presented by Li and Ford [26] with WC, TG, and SBP, while fasting insulin is substituted by FPG.

\section{Results}

\section{Population profile}

There were 16,711 individuals (87.0\% of the total 19,216 subjects we selected) who finished the questionnaire (6,658 men, $45.83 \pm 14.47$ years; 10,053 women, $40.77 \pm$ 12.13 years; gender ratio: female $/$ male $=1.51$ ). There were 688 subjects with no anthropometric, physiologic, or blood biochemical characteristic measurements were excluded. Afterwards, 8,551 people with anti-hypertensive, anti-dyslipidemic, or anti-hyperglycemic treatment were excluded. Therefore, 7,472 subjects were finally used for the analysis (2,666 men, $40.83 \pm 14.47$ years; 4,806 women, $40.77 \pm 12.13$ years), and gender ratio female/ male was 1.80 .

About $51.7 \%$ of male participants smoked every day versus only $2.9 \%$ in female. And $41.1 \%$ of men drank alcohol at least once a week, versus $3.3 \%$ of women. According to the last definition for MetS in 2009 [16], elevated WC was observed in $28.7 \%$ in men and $34.9 \%$ in women, elevated TG was seen in $23.4 \%$ of men and $10.5 \%$ of women; low HDL-C was detected in $15.9 \%$ of men and $35.7 \%$ of women; elevated blood pressure was observed in $46.3 \%$ of men and $29.3 \%$ of women; elevated FPG was seen in $21.5 \%$ of men and $15.9 \%$ of women. The prevalence of MetS, the cluster of three or more metabolic risk factors, was $21.5 \%$ in men and $16.9 \%$ in

Table 1 Means and standard deviations of physiological and anthrometric characteristics $(n=7,472)$

\begin{tabular}{|c|c|c|c|c|}
\hline \multirow[t]{2}{*}{ Measures } & \multicolumn{2}{|c|}{$\begin{array}{c}\text { Male } \\
(n=2,666)\end{array}$} & \multicolumn{2}{|c|}{$\begin{array}{c}\text { Female } \\
(n=4,806)\end{array}$} \\
\hline & Mean & SD & Mean & SD \\
\hline Height (cm) & 169.8 & 6.4 & $159.1^{\#}$ & 5.6 \\
\hline Weight (kg) & 70.0 & 11.0 & $59.8^{\#}$ & 9.2 \\
\hline Waist Curriculum (cm) & 84.5 & 9.7 & $76.8^{\#}$ & 9.3 \\
\hline Hip Curriculum (cm) & 97.0 & 6.9 & $95.5^{\#}$ & 7.3 \\
\hline Body Mass Index $\left(\mathrm{kg} / \mathrm{m}^{2}\right)$ & 24.2 & 3.3 & $23.6^{\#}$ & 3.5 \\
\hline Waist/hip Curriculum Ratio & 0.87 & 0.06 & $0.80^{\#}$ & 0.06 \\
\hline Systolic Blood Pressure $(\mathrm{mmHg})$ & 128.8 & 15.6 & $120.8^{\#}$ & 17.1 \\
\hline Diastolic Blood Pressure (mmHg) & 80.3 & 10.3 & $76.9^{\#}$ & 10.1 \\
\hline Mean Artery Pressure $(\mathrm{mmHg})$ & 96.5 & 11.2 & $91.5^{\#}$ & 11.8 \\
\hline Fasting Plasma Glucose* (mmol/L) & 5.29 & 1.05 & $5.14^{\#}$ & 0.83 \\
\hline Total Cholesterols (mmol/L) & 4.56 & 0.94 & 4.53 & 0.86 \\
\hline Triglyceride $^{*}$ (mmol/L) & 1.36 & 1.14 & $1.02^{\#}$ & 0.76 \\
\hline $\mathrm{HDL}-\mathrm{C}(\mathrm{mmol} / \mathrm{L})$ & 1.27 & 0.31 & $1.42^{\#}$ & 0.30 \\
\hline $\mathrm{LDL}-\mathrm{C}(\mathrm{mmol} / \mathrm{L})$ & 2.97 & 0.89 & $2.85^{\#}$ & 0.82 \\
\hline TG/HDL-C Ratio & 1.22 & 1.47 & $0.80^{\#}$ & 0.85 \\
\hline Creatinine $(\mu \mathrm{mol} / \mathrm{L})$ & 83.86 & 14.23 & $66.4^{\#}$ & 11.1 \\
\hline
\end{tabular}

*These values were $\log _{\mathrm{e}}$ transformed in confirmatory factor analysis;

\# These values are significant at $P<0.01$ compared with male counterparts; SD, standard deviation. 
women. The basic characteristics of the subjects were shown in Table 1.

\section{Confirmatory factor analysis (CFA)}

CFA was performed with AMOS v7.0, and the loadings for the factors in each model are shown in Figure 1 and Figure 2. Factor loadings were required to be greater than 0.30 and statistically significant $(P<0.05)$. In both models, all factor loadings were statistically significant. In Model 1, WC was the highest loading among the four factors, while FPG was the least. The loadings of TG/ HDL-C ratio and MAP were very close. TG/HDL-C ratio was a bit higher than MAP in men and senior women, while this was opposite in young and middle-aged women. In Model 2, WC was also the highest loading factor. TG was at the second place in men and in young and senior women; while SBP was the second highest loading factor in middle-aged women. FPG had the lowest score in both men and women.

Table 2 showed the fitness of models in each sex-age group. A $\chi^{2}$ test was used to evaluate if the hypothesized models fit the sample population. In either Model 1 or Model 2, the $X^{2}$ test had a $P>0.05$ in men and women aged above 60 . This indicated that the two single-models did not explain all of the relations among the measured variables in other age groups. However, as the $\chi^{2}$ test is prone to show a significant lack of model fit in studies with large sample size (over 1000 subjects), it was foreseeable that large $\chi^{2}$ value might be produced, and its results cannot be merely assessed in isolation. As a result, other indices were introduced. A model was considered to have a good fit when the CFI is more than 0.960 [27] and the SRMR is less than 0.080 [27]. The SRMR (standardized root mean square residual) was less than 0.080 in all age groups in Models 1 and 2. In Model 1, CFI (comparative fit index) was greater than 0.960 in male, and in female aged less than 60; in Model 2, CFI was plausible in every group except men aged 35-59. A model has a poor fit if RMSEA (root mean square error of approximation) is greater than 0.100; a mediocre fit is 0.080-0.100; and 0.050-0.080 means a reasonable fit; while a model has a good fit when the RMSEA is less than 0.050 [27]. According to this criteria, only Model 2 had a poor fit in middle-aged men.

In Table 3, fit indices were compared between the two competing models. GFI (goodness-of-fit index) showed how well a theoretical matrix could explain the matrix from a data sample. GFI ranges from 0 to 1 , and a higher score means a better fit [27]. Generally, GFI of more than 0.90 indicates a good model fit. Both the models in every age group had a sound GFI value. AIC (Akaike information criteria) takes into account the number of

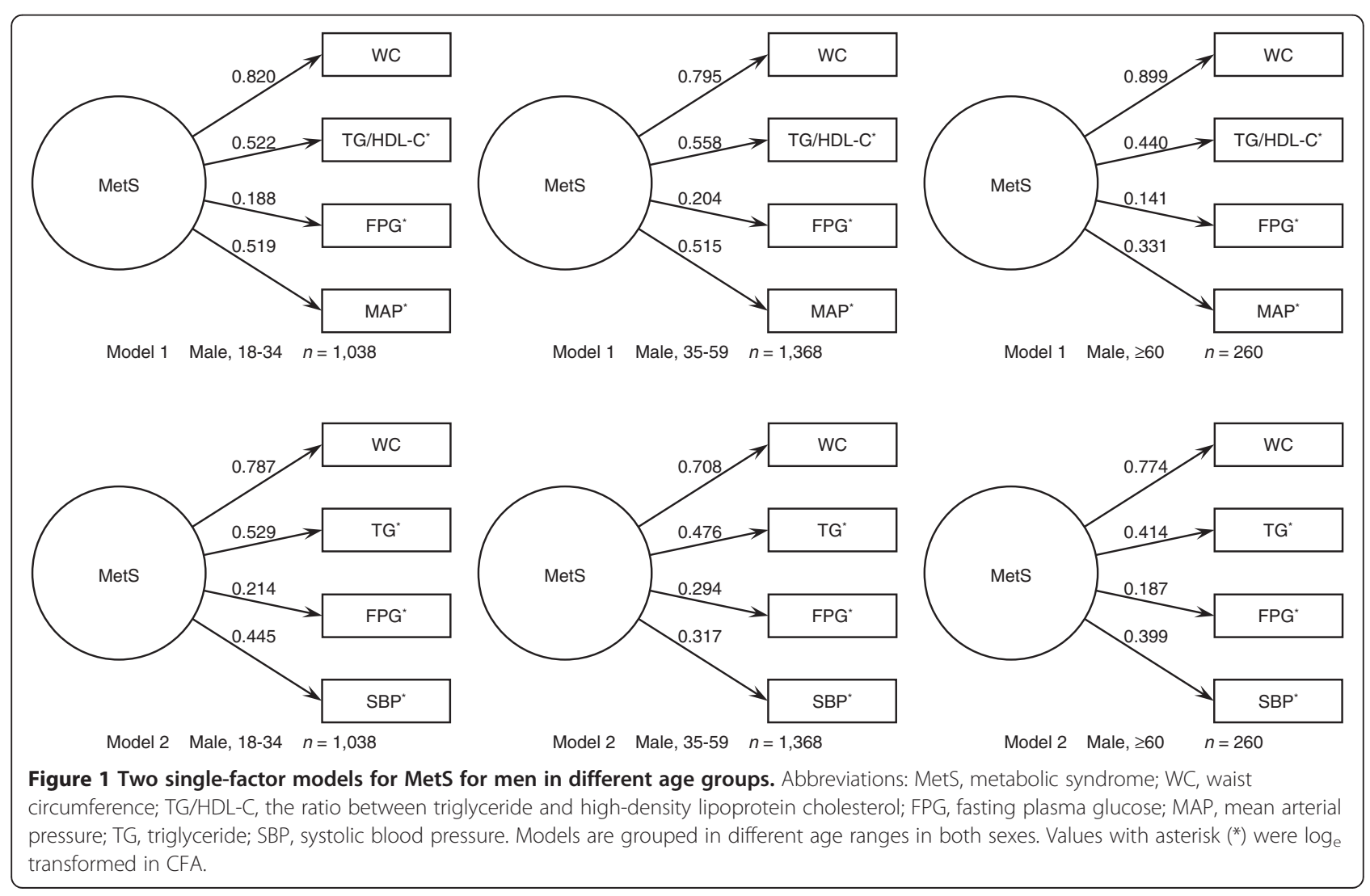




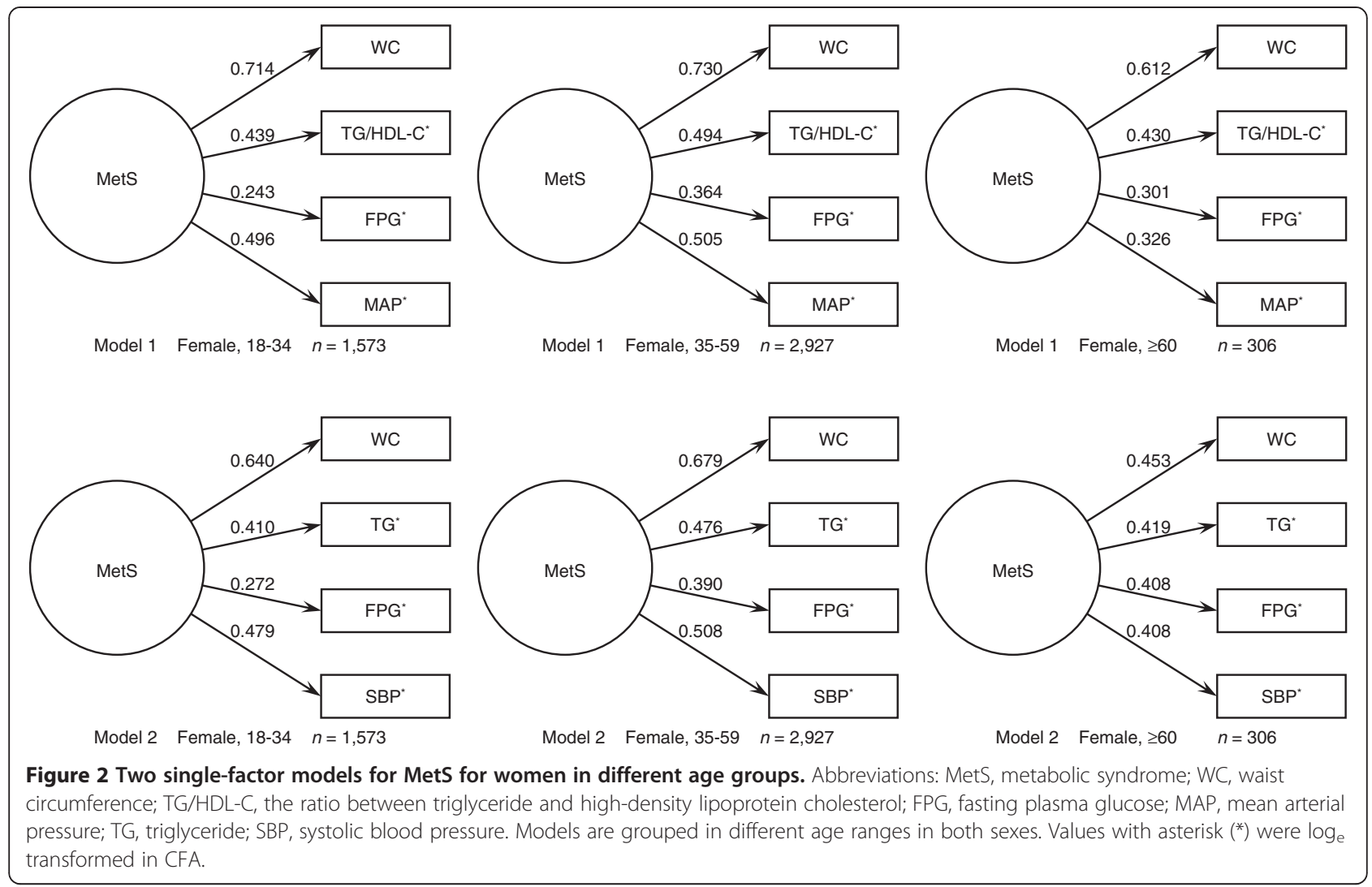

parameters of models under evaluation. It is an index to compare models with different latent variables. Models with a smaller AIC indicates a better fit $[27,28]$. Model 2 had a relative smaller value of AIC in every age group than Model 1, except in middle-aged men. BIC (Bayes information criterion) is similar to AIC in that both are derivatives of an information-theory based test. CAIC (consistent version of AIC) takes into the consideration of sample size effect. ECVI (expected cross-validation index) concerns the overall error. The indices above were used to compare fitness in different models [27]. Model 2 had a relative higher GFI and smaller AIC, BIC, CAIC, and ECVI than Model 1 in women over 35 and men in 18-34 and above 60; while in men of 35-59, Model 1 had a better fit in all set of indices. For young women, Model 2 had a larger GFI, smaller AIC and ECVI, whereas Model 1 had a smaller BIC and CAIC.

\section{Discussion}

Our results show that although in the same ethnic group, people from different sex-age groups must not be confirmed as one defined model. A number of published CFA studies have tested various hypothetical models, including 1-factor, 2-factor, 4-factor and second-order latent factor models [19-22,24], but there continues to be debate regarding which model best represents the factor structure for underlying cardiovascular risk factor clustering. But as a syndrome, there might be a core for the obvious disorders, and the single-factor model would be preferable.

In our study, WC is the leading factor for MetS. MetS is based on insulin resistance, however, the HOMA-IR is not available for this study, and WC is not the best but the most used manifest for that. It is consistent with former studies in other populations [24,29]. The models applied in different age groups have a great deal to do with the ultimate fit of the model. Regardless of how well specified the model is or its goodness of fit, factor analysis does not and cannot "prove" trait clustering or its physiological mechanism. Even confirmatory analyses are a function of a hypothetical model. In theory, there are an infinite number of alternative models that could fit data equally well or better and thereby produce the same covariance matrix. This is known as the equivalent models problem in structural equation modeling. Equivalent models are of particular concern for metabolic syndrome research and theory because such equivalent models may produce conflicting interpretations. In this study, Models 1 and 2 are examples of such conflicting models. In our study, Model 2 fitted the data in male of 18-34 and over 60 and in female of all age-groups, whereas Model 1 fitted male subjects of 35-59.

A prior CFA study had tested models similar to 1 and 2 , and found it to be valid and invariant across race and 
Table 2 Summary of statistics and model fit indices

\begin{tabular}{cccccccc}
\hline Model 1 & & & & & & & \\
& $\boldsymbol{X}^{2}$ & df & $\boldsymbol{P}$ value & SRMR & CFI & RMSEA & $\mathbf{9 0 \%}$ CI RMSEA \\
\hline Male & & & & & & & \\
$18-34$ & 4.976 & 2 & 0.083 & 0.0212 & 0.991 & 0.045 & $<0.001,0.096$ \\
$35-59$ & 8.255 & 2 & 0.016 & 0.0229 & 0.987 & 0.055 & $0.020,0.096$ \\
$\geq 60$ & 3.910 & 2 & 0.142 & 0.0344 & 0.973 & 0.061 & $<0.001,0.151$ \\
Female & & & & & & & \\
$18-34$ & 12.617 & 2 & 0.002 & 0.0226 & 0.977 & 0.058 & $0.030,0.091$ \\
$35-59$ & 38.287 & 2 & $<0.001$ & 0.0263 & 0.969 & 0.079 & $0.058,0.101$ \\
$\geq 60$ & 5.066 & 2 & 0.079 & 0.0334 & 0.938 & 0.071 & $<0.001,0.151$ \\
\hline Model 2 & & & & & & & \\
& $X^{2}$ & df & $\boldsymbol{P}$ value & SRMR & CFI & RMSEA & $\mathbf{9 0 \%}$ CI RMSEA \\
\hline Male & & & & & & & \\
$18-34$ & 7.047 & 2 & 0.030 & 0.0206 & 0.987 & 0.049 & $0.013,0.091$ \\
$35-59$ & 57.212 & 2 & $<0.001$ & 0.0516 & 0.849 & 0.142 & $0.112,0.175$ \\
$\geq 60$ & 3.892 & 2 & 0.143 & 0.0318 & 0.968 & 0.060 & $<0.001,0.150$ \\
Female & & & & & & & \\
$18-34$ & 8.579 & 2 & 0.014 & 0.0187 & 0.982 & 0.046 & $0.018,0.079$ \\
$35-59$ & 28.680 & 2 & $<0.001$ & 0.0229 & 0.975 & 0.068 & $0.047,0.090$ \\
$\geq 60$ & 3.107 & 2 & 0.212 & 0.0260 & 0.976 & 0.043 & $<0.001,0.129$ \\
\hline & & & & & & & \\
\hline
\end{tabular}

Table 3 Summary of models fit indices for two competing models

\begin{tabular}{ccccccc}
\hline Model 1 & & & & & & \\
& GFI & AIC & BIC & CAIC & ECVI & $\mathbf{9 0 \% ~ C I ~ E C V I ~}$ \\
\hline Male & & & & & & \\
$18-34$ & 0.996 & 24.255 & 63.816 & 71.816 & 0.023 & $0.018,0.036$ \\
$35-59$ & 0.986 & 58.367 & 100.135 & 108.135 & 0.043 & $0.030,0.061$ \\
$\geq 60$ & 0.993 & 19.910 & 48.396 & 56.396 & 0.077 & $0.069,0.115$ \\
Female & & & & & & \\
$18-34$ & 0.996 & 28.617 & 63.095 & 71.503 & 0.018 & $0.013,0.028$ \\
$35-59$ & 0.994 & 54.287 & 102.141 & 110.141 & 0.019 & $0.013,0.027$ \\
$\geq 60$ & 0.992 & 21.066 & 50.855 & 58.855 & 0.069 & $0.059,0.104$ \\
\hline Model 2 & & & & & & \\
& GFI & AIC & BIC & CAIC & ECVI & $\mathbf{9 0 \% ~ C I ~ E C V I}$ \\
\hline Male & & & & & & \\
$18-34$ & 0.997 & 23.047 & 62.607 & 70.607 & 0.022 & $0.018,0.034$ \\
$30-59$ & 0.981 & 73.211 & 114.981 & 122.981 & 0.054 & $0.038,0.074$ \\
$\geq 60$ & 0.993 & 19.892 & 48.377 & 56.377 & 0.077 & $0.069,0.115$ \\
Female & & & & & & \\
$18-34$ & 0.997 & 24.579 & 67.465 & 75.465 & 0.016 & $0.012,0.024$ \\
$35-59$ & 0.995 & 44.680 & 92.534 & 100.534 & 0.015 & $0.011,0.023$ \\
$\geq 60$ & 0.995 & 19.107 & 48.895 & 56.895 & 0.063 & $0.059,0.092$ \\
\hline & & & & & & \\
\hline
\end{tabular}

sex groups [24]. The model stability of MetS has been examined across sex $[20,26]$, ethnicity $[20,26]$, and age in a male population [30]. It seems that the theoretical model of MetS is consistent with few exceptions. In our study, the models fit differently in specific sex-age group. The concept of a single underlying factor that influences the expression of all observed traits is plausible. However, further longitudinal investigations are needed to explore the invariance of measurement, and to test the model structure stability with time.

This study indicated that the factor structure underlying the clustering of MetS in adults is varied in a population as Beijing's. The lack of fit and instability of the two models presented indicated that there might be variable components in the structure of MetS. Therefore, more research could be carried out to explore into the etiology of MetS.

There are also some limitations to this study. First, analyses were performed using cross-sectional data. Therefore, a temporal relationship was established between the studied MetS components. Second, as the requirement of CFA, the entry could only be analyzed with no missing value. Third, as the lack of measurement of fasting insulin, HOMA-IR and other indicators were not available to build the mature models such as the Pladevall et al.'s, Li and Ford's, and Martinez-Vizcaino et al.'s.

\section{Conclusions}

Our study confirms that MetS is a multi-factorial syndrome, and it suggests that there could be some patterns of common causation for the core components of MetS. This study preformed CFA in a Chinese population in Beijing, and suggests that the single-factor model of metabolic syndrome with WC, TG, FPG and SBP is plausible in women of all age group, and fits men in young adulthood and senior as well. The model with WC, TG/HDL-C ratio, FPG and MAP has better fit in men of middle-age.

\section{Methods}

Survey methodology and laboratory tests

In 2005, a surveillance of risk factors for noncommunicable diseases was conducted by Municipal Health Bureau and the Centers for Disease Control and Prevention (CDC) in Beijing, China. The cross-sectional study employed proportional multistage cluster random sampling design and selected 19,216 persons aged $\geq 18$ year-old who have lived in the city for at least six months. The survey was carried out during August and September, 2005. It included questionnaires, anthropometric and blood pressure measures, blood biochemical analysis. The questionnaire was composed of demographic profile as age, gender, educational background; risk factors of non-communicable diseases including smoking habit, alcohol consumption, diet, and physical 
exercise; prevalence of non-communicable diseases such as hypertension, type 2 diabetes mellitus, dyslipidemia, and overweight or obesity. The anthropometric measurements included weight, height, waist and hip circumference; blood pressure include systolic and diastolic pressures; and the laboratory examinations included fasting plasma glucose, total cholesterol, high-density lipoprotein cholesterol (HDL-C), low-density lipoprotein cholesterol (LDL-C), and creatinine. Detailed survey methodology, measurements and laboratory tests and was depicted elsewhere in 2010 [31]. This study was approved by the ethics committee of the Capital Medical University of China, and performed in accordance with the principles of Declaration of Helsinki (reference number: 2013SY26).

\section{Inclusion criteria and layered approach}

Primarily, there were 16,711 persons included in the database. 688 subjects with any missing value in sex, waist curriculum, systolic blood pressure, diastolic blood pressure, fasting plasma glucose, triglycerides, or HDL-C were excluded. 8,551 people with medication treatment within two weeks of tests were also excluded. At last, 7,472 individuals were remained under CFA. The age groups were divided as "18-34 years","35-59 years" and "over 60 years", which stood for young, middle-aged, and senior population, and models were analyzed in each age-group. There were 1,038, 1,368 and 260 male subjects in young, middle-aged and senior age-group, respectively; and 1,573, 2,927 and 306 female subjects in each age-group, respectively.

\section{Statistical analysis}

Continuous variables were expressed as means and standard deviations (SD), and discrete variables were presented as proportions. The study population met all requirements for factor analysis. In testing the normality assumption, five variables were found to have a high skewness - TG, TG/HDL-C ratio, FPG, SBP and MAP; these variables were transformed with a natural log function. The dichotomous variables used to define MetS risk factors were categorized by cut points of the latest definition [16]. The detailed diagnosis criteria are as follows:

-Obesity: $\geq 85 \mathrm{~cm}$ in men; $\geq 80 \mathrm{~cm}$ in women;

-Raised TG level (drug treatment for raised TG level is an alternative indicator): $\geq 150 \mathrm{mg} / \mathrm{dL}(1.7 \mathrm{mmol} / \mathrm{L})$;

-Reduced HDL-C level (drug treatment for reduced $\mathrm{HDL}-\mathrm{C}$ level is an alternative indicator): $<40 \mathrm{mg} / \mathrm{dL}$ $(1.0 \mathrm{mmol} / \mathrm{L})$ in $\mathrm{men} ;<50 \mathrm{mg} / \mathrm{dL}(1.3 \mathrm{mmol} / \mathrm{L})$ in women;

-Raised blood pressure (antihypertensive drug treatment in a patient with a history of hypertension is an alternate indicator): $\mathrm{SBP} \geq 130$ and/or $\mathrm{DBP} \geq 85 \mathrm{mmHg}$;
-Raised FPG level (drug treatment of raised glucose is an alternative indicator): $\geq 100 \mathrm{mg} / \mathrm{dL}(5.6 \mathrm{mmol} / \mathrm{L})$; -Participants fulfilling at least three out of these five components were diagnosed as having MetS.

The database was established by EpiData v3.02. The statistical analyses were performed using Statistical Package of Social Science for Windows v13.0 (SPSS Inc., Chicago, IL, USA). Statistical significance was set as $P<$ 0.05 .

To examine the construct validity of the two competing models for MetS, the CFA performed with maximum likelihood estimation using AMOS v7.0 (AMOS Development Co., Crawfordville, FL, USA).

\section{Consent}

Written informed consent was obtained from the patient for publication of this report and any accompanying images.

\section{Abbreviations}

MetS: Metabolic syndrome; WHO: World Health Organization;

IDF: International diabetes federation; NCEP: National Cholesterol Education Program; ATP III: Adult Treatment Panel III; CDS: Chinese Diabetes Society; JCDCG: Joint Committee for Developing Chinese Guidelines on Prevention and Treatment of Dyslipidemia in Adults; WC: Waist circumference;

TG: Triglycerides; SBP: Systolic blood pressure; DBP: Diastolic blood pressure; HDL-C: High density lipoprotein cholesterol; FPG: Fasting plasma glucose;

EFA: Exploratory factor analysis; CFA: Confirmatory factor analysis; MAP: Mean artery pressure; HOMA-IR: Homeostasis model of assessment for insulin resistance; SRMR: Standardized root mean square residual; CFI: Comparative fit index; RMSEA: Root mean square error of approximation; GFI: Goodness of fit index; AIC: Akaike information criteria; BIC: Bayes information criterion; CAIC: Consistent version of AIC; ECVI: Expected cross-validation index; CDC: Centers for disease control and prevention; LDL-C: Low density lipoprotein cholesterol; SD: Standard deviation.

\section{Competing interests}

The author declare that they have no competing interests.

\section{Authors' contributions}

$X G$ and $P Z$ designed the study; $W W$ and $D H$ participated in all data interpretation; DH drafted the manuscript; XL and QG carried out statistical analysis; LW, YL and YW critically reviewed the manuscript. All authors have read and approved the final manuscript.

\section{Acknowledgments}

This study was supported by Funding Project for The Program of Natural Science Fund of China (Serial Number: 81172772); The Major Project of Natural Science Fund of Beijing (Serial Number: 7131002,4112015); Key Projects in the National Science \& Technology Pillar Program in the Twelfth Five-year Plan Period of China (2011BAI08B01).

\section{Author details}

${ }^{1}$ School of Public Health, Capital Medical University, No.10 Xitoutiao, You'anmen Wai, Fengtai District, Beijing 100069, China. ${ }^{2}$ Beijing Municipal Key Laboratory of Clinical Epidemiology, Beijing 100069, China. ${ }^{3}$ Department of Integrated Early Childhood Development, Capital Institute of Pediatrics, No.2 Yabao Rd, Chaoyang District, Beijing 100020, China. ${ }^{4}$ The George Institute for Global Health at Peking University Health Science Center, Level 18, Tower B, Horizon Tower, No.6 Zhichun Rd, Haidian District, Beijing 100088, China. 


\section{References}

1. Alberti KG, Zimmet P, Shaw J: The metabolic syndrome-a new worldwide definition. Lancet 2005, 366:1059-1062.

2. Alberti KG, Zimmet P, Shaw J: Metabolic syndrome-a new world-wide definition. A consensus statement from the International Diabetes Federation. Diabet Med 2006, 23:469-480.

3. Rutter MK, Meigs JB, Sullivan LM, D'Agostino RB Sr, Wilson PW: Insulin resistance, the metabolic syndrome, and incident cardiovascular events in the Framingham Offspring Study. Diabetes 2005, 54:3252-3257.

4. Schmidt MI, Watson RL, Duncan BB, Metcalf P, Brancati FL, Sharrett AR, Davis CE, Heiss G: Clustering of dyslipidemia, hyperuricemia, diabetes, and hypertension and its association with fasting insulin and central and overall obesity in a general population. Atherosclerosis Risk in Communities Study Investigators. Metabolism 1996, 45:699-706.

5. Reaven GM: Banting lecture 1988. Role of insulin resistance in human disease. Diabetes 1988, 1988(37):1595-1607.

6. Ford ES, Giles WH, Dietz WH: Prevalence of the metabolic syndrome among US adults: findings from the third National Health and Nutrition Examination Survey. JAMA 2002, 287:356-359.

7. Grundy SM, Cleeman JI, Daniels SR, Donato KA, Eckel RH, Franklin BA, Gordon DJ, Krauss RM, Savage PJ, Smith SC Jr, et al: Diagnosis and management of the metabolic syndrome. An American Heart Association/National Heart, Lung, and Blood Institute Scientific Statement. Executive summary. Cardiol Rev 2005, 13:322-327.

8. Lakka HM, Laaksonen DE, Lakka TA, Niskanen LK, Kumpusalo E, Tuomilehto J, Salonen JT: The metabolic syndrome and total and cardiovascular disease mortality in middle-aged men. JAMA 2002, 288:2709-2716.

9. Haring R, Wallaschofski H, Nauck M, Felix SB, Schmidt CO, Dorr M, Sauer S, Wilmking G, Volzke H: Total and cardiovascular disease mortality predicted by metabolic syndrome is inferior relative to its components. Exp Clin Endocrinol Diabetes 2010, 118:685-691.

10. Kylin E: Studien ueber das Hypertonie-Hyperglyka "mie-Hyperurika" miesyndrom. Zentralblatt fuer Innere Medizin 1923, 44:105-127.

11. Alberti KG, Zimmet PZ: Definition, diagnosis and classification of diabetes mellitus and its complications. Part 1: diagnosis and classification of diabetes mellitus provisional report of a WHO consultation. Diabet Med 1998, 15:539-553.

12. Expert Panel on Detection Evaluation, and Treatment of High Blood Cholesterol in Adults: Executive Summary of The Third Report of The National Cholesterol Education Program (NCEP) Expert Panel on Detection, Evaluation, And Treatment of High Blood Cholesterol In Adults (Adult Treatment Panel III). JAMA 2001, 285:2486-2497.

13. Grundy SM, Cleeman JI, Daniels SR, Donato KA, Eckel RH, Franklin BA, Gordon DJ, Krauss RM, Savage PJ, Smith SC Jr, et al: Diagnosis and management of the metabolic syndrome: an American Heart Association/National Heart, Lung, and Blood Institute scientific statement. Curr Opin Cardiol 2006, 21:1-6.

14. Society EpomsoCd: Recommedations on metabolic syndrome of Chinese diabetes society. Chinese Journal of Diabetes 2004, 12:156-161.

15. Joint Committee for Developing Chinese Guidelines on Prevention and Treatment of Dyslipidemia in Adults: Chinese guidelines on prevention and treatment of dyslipidemia in adults. Zhonghua Xin Xue Guan Bing Za Zhi 2007, 35:390-419.

16. Alberti KG, Eckel RH, Grundy SM, Zimmet PZ, Cleeman JI, Donato KA, Fruchart JC, James WP, Loria CM, Smith SC Jr: Harmonizing the metabolic syndrome: a joint interim statement of the International Diabetes Federation Task Force on Epidemiology and Prevention; National Heart, Lung, and Blood Institute; American Heart Association; World Heart Federation; International Atherosclerosis Society; and International Association for the Study of Obesity. Circulation 2009, 120:1640-1645.

17. Mitka M: Does the metabolic syndrome really exist? Diabetes and heart disease groups spar over issue. JAMA 2005, 294:2010-2013.

18. Liese AD, Mayer-Davis EJ, Haffner SM: Development of the multiple metabolic syndrome: an epidemiologic perspective. Epidemiol Rev 1998, 20:157-172.

19. Hanson RL, Imperatore G, Bennett PH, Knowler WC: Components of the "metabolic syndrome" and incidence of type 2 diabetes. Diabetes 2002, 51:3120-3127

20. Shen BJ, Goldberg RB, Llabre MM, Schneiderman N: Is the factor structure of the metabolic syndrome comparable between men and women and across three ethnic groups: the Miami Community Health Study. Ann Epidemiol 2006, 16:131-137.
21. Novak S, Stapleton LM, Litaker JR, Lawson KA: A confirmatory factor analysis evaluation of the coronary heart disease risk factors of metabolic syndrome with emphasis on the insulin resistance factor. Diabetes Obes Metab 2003, 5:388-396.

22. Langer DA, Wood JJ, Bergman RL, Piacentini JC: A multitrait-multimethod analysis of the construct validity of child anxiety disorders in a clinical sample. Child Psychiatry Hum Dev 2010, 41:549-561.

23. Bentler PM: EQS Structural Equation Program Manual. Encino, California: Multivariate Software; 1995:272. ISBN 10: 1885898029, 13: 978-1885898029.

24. Pladevall M, Singal B, Williams LK, Brotons C, Guyer H, Sadurni J, Falces C, Serrano-Rios M, Gabriel R, Shaw JE, et al: A single factor underlies the metabolic syndrome: a confirmatory factor analysis. Diabetes Care 2006, 29:113-122.

25. Martinez Vizcaino V, Salcedo Aguilar F, Franquelo Gutierrez R, Solera Martinez M, Sanchez Lopez M, Serrano Martinez S, Lopez Garcia E, Rodriguez Artalejo F: Assessment of an after-school physical activity program to prevent obesity among 9- to 10-year-old children: a cluster randomized trial. Int J Obes (Lond) 2008, 32:12-22.

26. Li C, Ford ES: Is there a single underlying factor for the metabolic syndrome in adolescents? A confirmatory factor analysis. Diabetes Care 2007, 30:1556-1561.

27. Hu L, Bentler PM: Cutoff criteria for fit indexes in covariance structure analysis: conventional criteria versus new alternatives. Structural Equation Modeling: A Multidisciplinary Journal 2009, 6:1-55.

28. Kline RB: Principles and Practice of Structural Equation Modeling. New York: Guilford Press; 1998.

29. Leyva F, Godsland IF, Ghatei M, Proudler AJ, Aldis S, Walton C, Bloom S, Stevenson JC: Hyperleptinemia as a component of a metabolic syndrome of cardiovascular risk. Arterioscler Thromb Vasc Biol 1998, 18:928-933.

30. Shen BJ, Todaro JF, Niaura R, McCaffery JM, Zhang J, Spiro A 3rd, Ward KD: Are metabolic risk factors one unified syndrome? Modeling the structure of the metabolic syndrome X. Am J Epidemiol 2003, 157:701-711.

31. Liu Y, Zhang P, Wang W, Wang H, Zhang L, Wu W, Guo X: The characteristics of dyslipidemia patients with different durations in Beijing: a cross-sectional study. Lipids Health Dis 2010, 9:115.

doi:10.1186/1476-511X-12-61

Cite this article as: Huo et al:: Evaluation of two single-factor models of metabolic syndrome: a confirmatory factor analysis for an adult population in Beijing. Lipids in Health and Disease 2013 12:61.

\section{Submit your next manuscript to BioMed Central and take full advantage of:}

- Convenient online submission

- Thorough peer review

- No space constraints or color figure charges

- Immediate publication on acceptance

- Inclusion in PubMed, CAS, Scopus and Google Scholar

- Research which is freely available for redistribution 